\title{
Environmental fluid mechanics in hydraulic engineering
}

\author{
Hubert Chanson $^{1}$ (D) Fabian Bombardelli ${ }^{2}$ D $\cdot$ Oscar Castro-Orgaz $^{3}$ (D)
}

Received: 19 January 2020 / Accepted: 22 January 2020 / Published online: 6 March 2020 (c) Springer Nature B.V. 2020

Keywords Environmental fluid mechanics · Hydraulic engineering · Open channel flows · Theoretical analysis $\cdot$ Physical modelling $\cdot$ Numerical modelling

\section{Presentation}

Water is an indispensable element for life on Earth, and covers $71 \%$ of our planet's surface; further, humans associate water with environment. Hydraulic engineers are at the forefront of scientific developments to deliver water to communities, and to protect our society from water-related disasters $[1,2]$. The technical tasks faced by hydraulic engineers are formidable, and sustained research efforts are essential to provide some basic understanding of different phenomena, as well as to furnish predictors for design. In particular, the scientific challenges in environmental fluid flows are significant: "there is so much to be gained by giving heed to rationale methods of analysis and research" [3, p. x]. The extreme levels of complexity are closely linked to the variety of water systems, the broad range of relevant time and length scales, the variability of river flows from droughts to gigantic floods, the complexity of basic fluid mechanics with non-linear governing equations, flow instabilities, interactions between water, solid and air phases, and with fauna and flora.

Environmental fluid mechanics encompasses the scientific studies broadly relating to natural fluid systems on our planet (i.e., air and water) affecting the environmental quality of life [4]. Understanding transport and diffusion/dispersion processes in natural fluid flows, from the sub-millimetric scale to the planetary scale, serves as the impetus for the development of theoretical models, simulations and predictions, leading ultimately to sustainable environmental management. Altogether, the subject areas are diverse and may originate from a variety of scientific and engineering disciplines: civil, mechanical and

Hubert Chanson

h.chanson@uq.edu.au

Fabian Bombardelli

fabianbombardelli2@gmail.com

Oscar Castro-Orgaz

ag2caoro@uco.es

1 School of Civil Engineering, The University of Queensland, Brisbane, QLD 4072, Australia

2 Department of Civil and Environmental Engineering, University of California Davis, One Shields Ave., Davis, CA 95616, USA

3 Hydraulic Engineering Area, University of Cordoba, Campus Rabanales, Leonardo Da Vinci Building, 14071 Córdoba, Spain 
(A, Left) Nobbys Beach, Newcastle NSW (Australia) on 29 October 2019 (Photograph H. CHANSON)

(B, Right) Large river near Taichung (Taiwan) on 4 December 2017 (Photograph H. CHANSON)
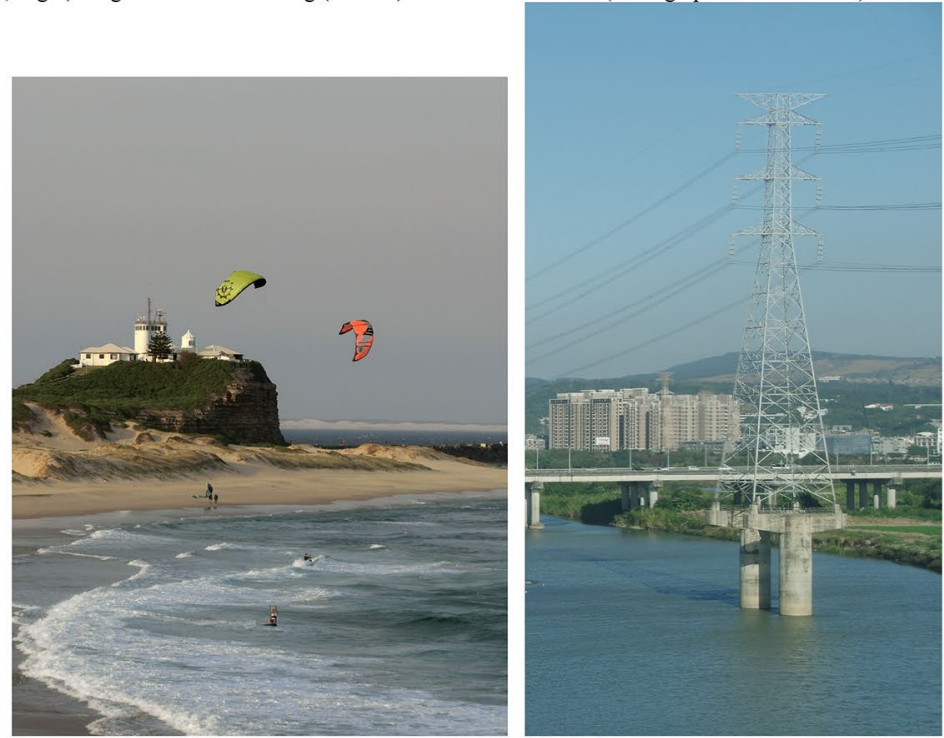

(C) Meuse River at Maastricht (The Netherlands) on 12 May 2018 (Photograph H. CHANSON)

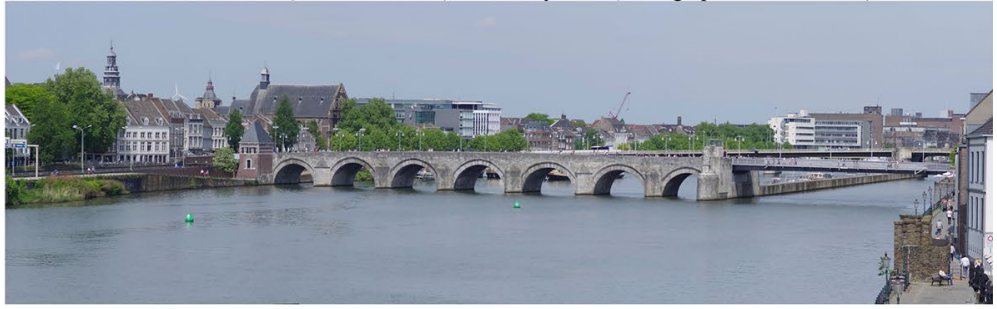

(D) Brisbane River in Brisbane QLD (Australia) on 20 October 2020 (Photograph H. CHANSON)

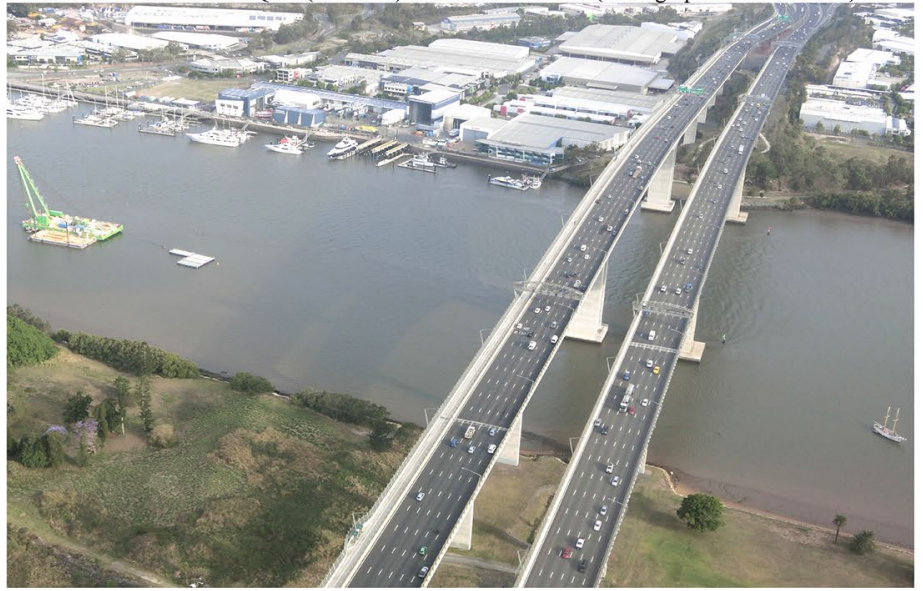

Fig. 1 Environmental hydraulic situations 
(E) Canals in La Petite France, Strasbourg (France) on 21 June 2019 (Photograph H. CHANSON)

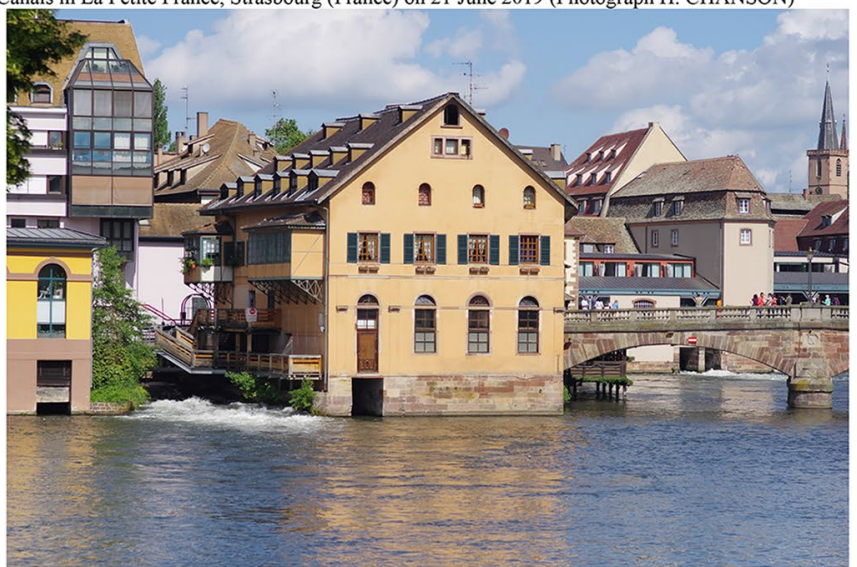

(F) Culvert inlet blocked by large amount of wooden debris in Aachen (Germany) on 1 May 2018 (Photograph H. CHANSON)

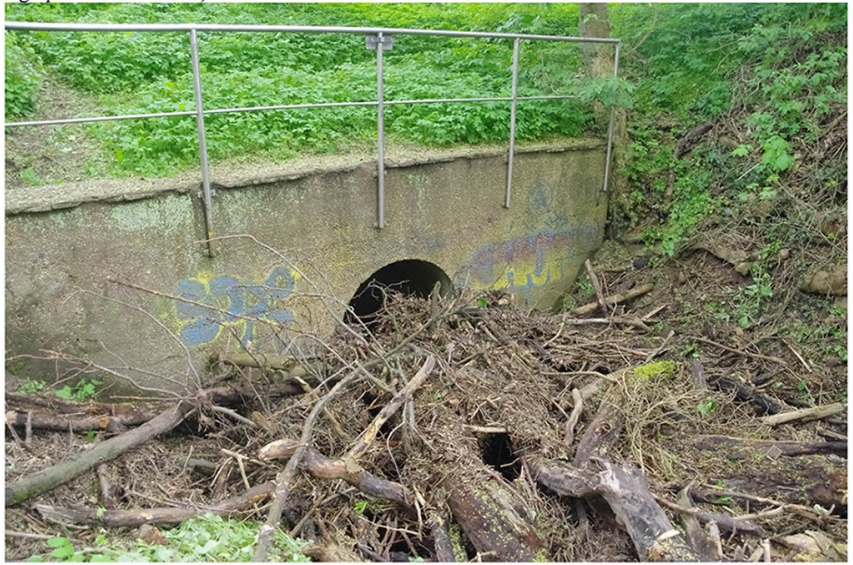

(G) Labyrinth weir at the crest of the Shilin Dam spillway, on the Daan River (Taiwan) on 9 January 2016 (Photograph H. CHANSON)

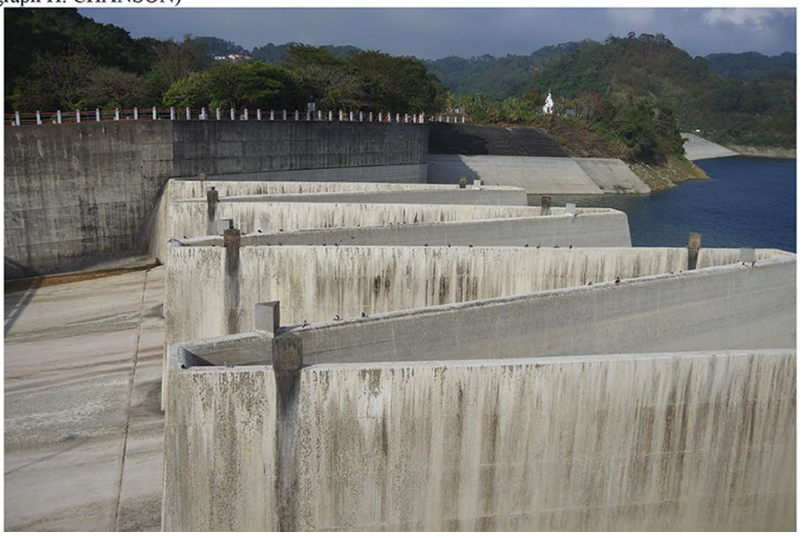

Fig. 1 (continued) 
environmental engineering, meteorology, hydrology, hydraulics, limnology, and oceanography (Fig. 1). In Fig. 1, a small range of relevant environmental fluid mechanics situations, encompassing coastal, estuarine and riverine systems, is presented, illustrating the complicated interactions between Mankind and the Environment.

Following of Hunter Rouse's classical text "Fluid Mechanics for Hydraulic Engineers" [3], the aim of this Special Issue (SI) is to present a group of papers that summarise the state-of-the-art of the fluid dynamics of hydraulic flows, in environmental geophysical and man-made applications, at the time of reporting novel pathways in research. The SI contains contributions on the topic, as "a concerted effort to reconcile the theories of classical hydrodynamics with the findings of the practical engineer" [3, p. ix].

\section{Special issue contents}

A total of ten papers were accepted after a rigorous peer-review process, with contributors from eight countries across four continents. The scope of the Special Issue (SI) is broad, with four studies on fluvial hydraulics, one on coastal hydraulics, and seven on hydraulic structures. The latter topic encompasses advanced multidisciplinary subjects such as gas-liquid multiphase flow, and fish passage. The papers of the SI include contributions on experimental, theoretical and numerical modelling, as well as combined approaches embedding more than two or more methodologies, e.g., hybrid modelling. Altogether the SI regroups four physical studies, six numerical investigations, all of them being computational fluid dynamics (CFD) studies, and two theoretical analyses. Furthermore, several contributions embed two or more approaches. Clearly, environmental fluid mechanics does bring new challenges as well as solutions directly relevant to hydraulic engineering broadly.

The paper by De Padova et al. [5] focuses on the vorticity field during wave breaking. Using smooth particle hydrodynamics ( $\mathrm{SPH}$ ) methodology, both spilling and plunging breaking waves were modelled. The findings show that vorticity is generated first beneath the free-surface at the onset of breaking.

Castro-Orgaz and Cantero-Chinchilla [6] investigate the effects of bed topography on shallow water free-surface flow. They presented the two-dimensional unsteady form of the Serre-Green-Naghdi equations, and obtained an accurate solution of the non-hydrostatic pressure flow field and undular free surface over obstacles.

The following two papers deal with the effect of non-uniform bed roughness on steady fluvial flow. $\mathrm{Li}$ and $\mathrm{Li}$ [7] measured the near-bed velocity field above regularly-distributed large roughness elements for a range of element spacing. Both d-type and k-type roughness boundary conditions are discussed, including the secondary flow motion. Cassan et al. [8] analyse the effect of spatial roughness distribution along fixed boundaries. Based upon a simplified solution of the Navier-Stokes equations, the boundary shear stress distribution may be derived along the wetted perimeter.

Pagliara et al. [9] investigate physically the effects of channel curvature on sediment processes downstream of weirs equipped with a block ramp. They develop a design relationship between the maximum scour depth and the curvature of the river.

Carrillo et al. [10] analyse numerically the overflow above a labyrinth weir. With validation against physical data, the numerical approach reproduced successfully the discharge relationship of the un-aerated overflow. The authors discuss further a number of challenges and un-resolved issues. 
Zabaleta et al. [11] addressed the physical mechanisms leading to free-surface aeration process above a stepped spillway. Using computational fluid dynamics, they show that the step edges act as vorticity generators, while self-aeration is directly linked to the interactions of coherent structures with the free-surface.

Jesusdhas et al. [12] focus on the computational fluid dynamics modelling of hydraulic jumps at relatively high Froude numbers. After a comparison of the numerical modelling results against physical data set, the different physical mechanisms contributing to air entrainment are discussed based upon the numerical outputs. The results show in particular complicated three-dimensional processes, consistent with recent experimental observations.

Two contributions are focused on upstream passage of small fish in standard box culverts. Leng and Chanson [13] use computational fluid dynamics to model the low-velocity zone (LVZ) on smooth box culverts operating with less than design flow conditions. They obtain a self-similar relationship between the LVZ size and the targeted fish swimming speed, which may be used to develop fish-friendly culvert design guidelines. Sailema et al. [14] study experimentally an alternative approach, using small triangular corner baffles, with a focus on providing some low positive velocity zone (LPVZ). Two novel designs are proposed with ventilation to reduce the adverse effect of the baffle wake on small-bodied fish.

Finally, one may conclude that the advances in the field have been steady and considerable since Hunter Rouse's textbook [3], but that many more challenges remain un-resolved. The issue of fish-fluid interactions is an unsolved one; sediment transport and scour process still require more work and understanding; self-aeration at hydraulic structures must be embedded in the hydraulic design [15]. New experimental techniques, numerical models as well as combined modelling approaches will be needed to address many of these challenges. Future research must further encompass new high-quality field measurements, performed in situ at the full scale. In many applications, a major challenge of prototype scale hydraulic flows is their two- or three-phase nature that may include water, air and sediments.

Acknowledgements The guest editors (HC, FB, OCO) thank all the contributors of the special issue, as well as all the reviewers, without whom this SI would not have been possible. They would also like to acknowledge Professor H.J. Fernando, Editor-in-Chief of the journal, for his support and leadership.

\section{References}

1. Chanson H (2007) Hydraulic engineering in the 21st century: where to? J Hydraul Res 45(3):291-301. https://doi.org/10.1080/00221686.2007.9521764

2. Chanson H (2008) The known unknowns of hydraulic engineering. Eng Comput Mech 161(EM1):1725. https://doi.org/10.1680/eacm.2008.161.1.17

3. Rouse H (1938) Fluid mechanics for hydraulic engineers. McGraw-Hill, New York (also Dover Publ., New York, USA, 1961, 422 pages)

4. Cushman-Roisin B, Gualtieri C, Mihailovic DT (2008) Environmental fluid mechanics: current issues and future outlook. In: Gualtieri C, Mihailovic DT (eds) Fluid mechanics of environmental interfaces. Taylor \& Francis, Leiden, pp 1-13

5. De Padova D, Ben Meftah M, De Serio F, Mossa M, Sibilla S (2020) Characteristics of breaking vorticity in spilling and plunging waves investigated numerically by SPH. Environ Fluid Mech. 20. https:// doi.org/10.1007/s10652-019-09699-5 
6. Castro-Orgaz O, Cantero-Chinchilla FN (2020) Non-linear shallow water flow modelling over topography with depth-averaged potential equations. Environ Fluid Mech 20:31. https://doi.org/10.1007/s1065 2-019-09691-z

7. Li J, Li SS (2020) Near-bed velocity and shear stress of open-channel flow over surface roughness. Environ Fluid Mech 20:28. https://doi.org/10.1007/s10652-019-09728-3

8. Cassan L, Roux H, Dartus D (2020) Velocity distribution in open channel flow with spatially distributed roughness. Environ Fluid Mech 20:18. https://doi.org/10.1007/s10652-019-09720-x

9. Pagliara S, Palermo M, Roy D (2020) Experimental investigation of erosion processes downstream of block ramps in mild curved channels. Environ Fluid Mech. 20. https://doi.org/10.1007/s10652-01909681-1

10. Carrillo JM, Matos J, Lopes R (2020) Numerical modeling of free and submerged labyrinth weir flow for a large sidewall angle. Environ Fluid Mech. 20. https://doi.org/10.1007/s10652-019-09701-0

11. Zabaleta F, Bombardelli FA, Toro JP (2020) Towards an understanding of the mechanisms leading to air entrainment in the skimming flow over stepped spillways. Environ Fluid Mech. 20. https://doi. org/10.1007/s10652-019-09729-2

12. Jesusdhas V, Balachandar R, Wang H, Murzyn F (2020) Modelling hydraulic jumps: IDDES versus experiments. Environ Fluid Mech. 20. https://doi.org/10.1007/s10652-019-09734-5

13. Leng X, Chanson H (2020) Hybrid modelling of low velocity zones in box culverts to assist upstream fish passage. Environ Fluid Mech. 20. https://doi.org/10.1007/s10652-019-09700-1

14. Sailema C, Freire R, Chanson H, Zhang G (2020) Modelling small ventilated corner baffles for box culvert barrel. Environ Fluid Mech. 20. https://doi.org/10.1007/s10652-019-09680-2

15. Chanson H, Leng X, Wang H (2019) Bubbles, transient turbulence and fish-challenging hydraulic structures of the 21 st century. In: Calvo L (ed) Proceedings of the 38th IAHR world congress. IAHR Publication, Panama City

Publisher's Note Springer Nature remains neutral with regard to jurisdictional claims in published maps and institutional affiliations. 